Jurnal Semarak,Vol. 3,No.1, Februari 2020, Hal (75- 81)

@Prodi Manajemen Fakultas Ekonomi Universitas Pamulang

\title{
PENGARUH KOMUNIKASI DAN DISIPLIN KERJA \\ TERHADAP KINERJA KARYAWAN \\ PADA PT. RAMAYANA LESTARI SENTOSA.TBK DI JAKARTA PUSAT
}

\author{
Agustina Mogi, S.Si., M.M. \\ Asisten Ahli Fakultas Ekonomi Universitas Pamulang \\ Email : $\underline{\text { dosen01557@ unpam.ac.id }}$
}

\begin{abstract}
ABSTRAK
Tujuan penelitian ini adalah untuk mengetahui dan menganalisa seberapa besarnya pengaruh antara komunikasi terhadap kinerja karyawan, pengaruh disiplin terhadap kinerja karyawan, serta untuk mengetahui dan menganalisa besarnya pengaruh komunikasi dan disiplin kerja terhadap kinerja karyawan secara simultan pada PT. Ramayana Lestari Sentosa. Tbk, dengan jumlah populasi 50 karyawan dan sampel yang di ambil sebanyak 50 dengan teknik sampel jenuh. Metode deskriptif kuantitatif digunakan penulis karena pendekatan ini menggambarkan permasalahan untuk menentukan seberapa besarnya pengaruh variabel independen yaitu antara Komunikasi dan Disiplin Kerja dengan variabel dependen (Kinerja Karyawan). Selanjutnya, dilakukan pengujian hipotesis. Berdasarkan hasil olah data, nilai konstanta sebesar 3,090 menyatakan bahwa jika ada peningkatan dari variabel komunikasi (X1) dan Disiplin kerja (X2) nilainya 0, maka Kinerja karyawan (Y) nilainya 3.090. Nilai koefisien korelasi 0,748 artinya ada hubungan yang kuat, nilai determinasi sebesar 56\%. Variabel komunikasi secara parsial berpengaruh positif dan signifikan terhadap kinerja karyawan dengan nilai t hitung $6,411>2,011$ dan nilai sig $0,000<0,05 \mathrm{Hal}$ ini menunjukan bahwa $\mathrm{H}_{01}$ ditolak dan $\mathrm{H}_{\mathrm{a} 1}$ diterima. Variabel disiplin kerja secara parsial berpengaruh positif dan signifikan terhadap kinerja karyawan dengan nilai $t$ hitung 6,017>2,011 dan nilai sig $0,000<0,05$ hal ini menunjukan bahwa $\mathrm{H}_{02}$ ditolak dan $\mathrm{H}_{\mathrm{a} 2}$ diterima. Sehingga, jika nilai variabel komunikasi naik maka kinerja karyawan akan meningkat. Variabel komunikasi dan disiplin kerja secara simultan berpengaruh positif dan signifikan terhadap kinerja karyawan. Berdasarkan uji hipotesis F (Simultan) dapat diketahui bahwa nilai Fhitung 29, $879>2,800$ dan nilai signifikan $0,000<0,05$ maka dapat di simpulkan bahwa $\mathrm{H}_{03}$ ditolak dan $\mathrm{H}_{\mathrm{a} 3}$ diterima, hal ini berarti komunikasi dan disiplin kerja secara simultan berpengaruh positif dan signifikan terhadap kinerja karyawan pada PT. Ramayana Lestari Sentosa.Tbk.
\end{abstract}

Kata kunci :Komunikasi, Disiplin Kerja, Kinerja Karyawan.

\begin{abstract}
The purpose of the research that the author is doing is to know and analyze the magnitude of the influence of communication on employees ' performance, to know and analyse the magnitude of the discipline impact of employee performance, and to know and Analyze the magnitude of communication and work discipline on the simultaneous performance of employees at PT. Ramayana Lestari Sentosa. TBK, with a population number of 50 employees and samples taken as much as 50 with a Junuh sample technique. The research method used by the authors is a quantitative descriptive method aimed at knowing the influence between two or more variables, where this approach provides an overview of the
\end{abstract}


problem to find influences between the $\mathrm{X} 1$ variables (Communication) and variable X2 (working discipline) with a variable Y (employee performance) then conducted a hypothesis test to determine whether a proposed hypothesis was received or rejected by using a regression analysis. The test is used to test the research instrument in the form of validity test and reusability test. Hypothesis tests using $\mathrm{T}$ tests (partial), test (simultaneous), multiple linear regression analyses, correlation coefficient and determination with the help of Software SPSS 24 for Windows. Based on the multiple regression test results A constant value of 3.090 states that if there is an increase of the communication variables (X1) and the Working Discipline (X2) value of 0 , then the employee performance (Y) value is 3,090 . Correlation coefficient value 0.748 means there is a strong relationship, the determination value of $56 \%$. Communication variables partially affect the positive and significant of the employee's performance by the calculated $\mathrm{T}$ value $6,411>2,011$ and the value of sig $0,000<0.05$ This indicates that the HO1 was rejected and HA1 accepted. Work discipline variables partially influence positive and significant impact on employee performance by the calculated $\mathrm{T}$ value $6,017>2,011$ and the sig value $0,000<0.05$ This indicates that Ho2 are rejected and HA2 accepted. Thus, if the value of the communication variable rises then the employee's performance will increase. Communication variables and work disciplines simultaneously have a positive and significant impact on employee performance. Based on the $\mathrm{F}$ (simultaneous) hypothesis test it can be noted that the value of Fcount 29, $879>2,800$ and the significant value $0,000<0.05$ then can be concluded that $\mathrm{Ho} 3$ rejected and $\mathrm{Ha} 3$ accepted, this means that communication and work discipline simultaneously positively and significantly affect the performance of employees at PT. Ramayana Lestari Sentosa. Tbk.

\section{Keywords: Communication, Work Discipline, Employee Performance.}

\section{PENNDAHULUAN}

\section{A. Latar Belakang}

Dalam observasi dengan menggali informasi dari salah satu karyawan ditemukan kurangnya peran pemimpin dalam memberi arahan atau kurangnya komunikasi yang kurang baik dan motivasi sehingga karyawan kurang bersemangat. Selain itu dalam observasi juga ditemukan kurangnya kepedulian manajemen dalam mengakomodir aspirasi dan ide-ide dari para karyawan divisi pajak pada PT. Ramayana Lestari Sentosa Tbk Jakarta Pusat.
Hasil survey awal yang penulis lakukan terhadap 30 karyawan pada divisi pajak pada PT. Ramayana Lestari Sentosa Tbk Jakarta Pusat dapat dilihat pada tabel berikut.

Tabel 1.1

Rekapitulasi Hasil ObservasiVariabel Komunikasi

\begin{tabular}{|c|l|c|c|}
\hline \multirow{2}{*}{ No } & \multicolumn{2}{|c|}{ Pertanyaan } & \multicolumn{2}{|c|}{ Jawaban } \\
\cline { 3 - 4 } 1 & $\begin{array}{l}\text { Apakah pimpinan } \\
\text { dapat bersikap } \\
\text { ramah kepada } \\
\text { anda. }\end{array}$ & 13 & Tidak \\
\hline 2 & $\begin{array}{l}\text { Apakah pimpinan } \\
\text { anda mampu } \\
\text { menunjukan } \\
\text { kepedulian }\end{array}$ & 9 & 21 \\
\hline
\end{tabular}




\begin{tabular}{|c|l|c|c|}
\hline & $\begin{array}{l}\text { terhadap } \\
\text { karyawan. }\end{array}$ & \\
\hline 3 & $\begin{array}{l}\text { Apakah } \\
\text { perusahaan } \\
\text { memberikan } \\
\text { penghargaan } \\
\text { kepada karyawan } \\
\text { yang melakukan } \\
\text { pekerjaan dengan } \\
\text { baik. }\end{array}$ & 14 \\
\hline 4 & $\begin{array}{l}\text { Apakah pimpinan } \\
\text { anda selalu } \\
\text { memberikan } \\
\text { kepercayaan } \\
\text { kepada } \\
\text { karyawaan. }\end{array}$ & 15 \\
\hline $\begin{array}{l}\text { Sumber: Hasil Survey yang sudah diolah } \\
\text { oleh peneliti, 2019. }\end{array}$
\end{tabular}

Berdasarkan tabel di atas, diketahui jika komunikasi yang dimiliki oleh karyawan dan pimpinan yang ada di divisi pajak pada PT. Ramayana Lestari Sentosa
Tbk Jakarta Pusat masih terbilang kurang baik. Berdasarkan observasi dan pengamatan yang peneliti lakukan. Sikap keramahan dan kepedulian pimpinan mayoritas dijawab dengan kata tidak oleh karyawan yang menjadi responden pada survey awal, begitu juga dengan pertanyaan terkait dengan penghargaan karyawan yang melakukan pekerjaan dengan baik mayoritas dijawab dengan kata tidak setuju dengan pertanyaan tersebut. Faktor berikutnya yang juga berpengaruh untuk mencapai tujuan perusahaan adalah disiplin kerja.

Berikut disajikan hasil pengukuran disiplin kerja karyawan pada PT. Ramayana Lestari Sentosa.Tbk Jakarta Pusat selama kurun waktu 3 (tiga) tahun dari mulai 2016 s/d 2018 yaitu:

Tabel 1.2

Data Disiplin Kerja (Absensi) PT. Ramayana Lestari Sentosa.Tbk Jakarta Pusat Tahun 2016 - 2018.

\begin{tabular}{|c|c|c|c|c|c|c|c|c|}
\hline \multirow[b]{2}{*}{ Tahun } & \multirow{2}{*}{$\begin{array}{l}\text { Jumlah } \\
\text { Pegawai }\end{array}$} & \multicolumn{5}{|c|}{ Kriteria (Jumlah Karyawan) } & \multirow{2}{*}{$\begin{array}{l}\text { Jumlah } \\
\text { Absensi }\end{array}$} & \multirow[b]{2}{*}{$(\%)$} \\
\hline & & JHK & Terlambat & Sakit & Izin & Abstain & & \\
\hline 2016 & 65 & 250 & 45 & 16 & 20 & 10 & 91 & $36,4 \%$ \\
\hline 2017 & 65 & 250 & 32 & 10 & 18 & 20 & 80 & $32,0 \%$ \\
\hline 2018 & 60 & 250 & 35 & 17 & 10 & 20 & 82 & $32,8 \%$ \\
\hline
\end{tabular}

Sumber : Data primer diolah PT. . Ramayana Lestari sentosa.Tbk Jakarta Pusat 2019

Tabel 1.2, menunjukkan tahun 2016 jumlah terlambat, sakit izin dan absen mendapat 91 orang atau $36,4 \%$ dari jumlah hari kerja (JHK). Tahun 2017 turun menjadi $32 \%$ namun tahun 2018 mengalami kenaikan menjadi $32,8 \%$.

Organisasi berhasil karena adanya tanggung jawab dari karyawan yang tepat waktu saat masuk
kerja.Namun dari observasi yang telah dilakukan karyawan masih banyak yang telat saat masuk jam kerja, kurang komunikasi antar karyawan dengan pimpinan, saat jam kerja keluar dari kantor, dan menunda tugas kantor. Hal tersebut tentunya dapat mempengaruhi kinerja pada masing-masing individu.

Menurut Machmed (2014:187) Komunikasi dan disiplin kerja sangat 
berpengaruh terhadap kinerja PT. Ramayana Lestari karyawan. Kinerja adalah tingkat Sentosa.Tbk menilai kinerja karyawan efektivitas dan efesiensi yang dari membandingkan jumlah target ditunjukan oleh karyawan dalam kinerja dengan realisasi kinerja setiap melaksanakan tugasnya sehari-hari di tahun. Berikut ini tabel target dan suatu organisasi atau perusahaan pada realisasi kinerja di PT. Ramayana priode tertentu.

Tabel 1.3

Lestari Sentosa.tbk dari tahun 2016 sampai 2018 sebagai berikut.

Target Kinerja dan Realisasi di PT. Ramayana Lestari Sentosa. Tbk Jakarta Pusat Periode Tahun 2016-2018

\begin{tabular}{|c|c|c|c|}
\hline Tahun & Target Kinerja Karyawan & $\begin{array}{c}\text { Realisasi Kinerja } \\
\text { Karyawan }\end{array}$ & Persentase \\
\hline 2016 & 100 & 85 & $85 \%$ \\
\hline 2017 & 100 & 95 & $95 \%$ \\
\hline 2018 & 100 & 93 & $93 \%$ \\
\hline
\end{tabular}

Sumber: Data primer diolah PT. Ramayana Lestari sentosa.Tbk 2019

Berdasarkan pada data tabel di atas, menunjukan bahwa realisasi kinerja karyawan keseluruhan pada tahun 2016 sebesar 85\%. Tahun 2017, realisasi kinerja karyawan mengalami kenaikan sangat signifikan yaitu menjadi 95\%. Pada tahun 2018 realisasi kinerja karyawan mengalami penuruan kembali yaitu hanya mencapai 93\%. Hal ini menunjukan bahwa kinerja karyawan rendah, karena tidak mencapai target yang diingingkan perusahaan.

\section{B. Rumusan Masalah}

Setelah dilakukan penjabaran dalam analisis, dapat dibuat suatu perumusan masalah adalah:

1. Bagaimana pengaruh komunikasi terhadap kinerja karyawan pada PT. Ramayana Lestari Sentosa Tbk di Jakarta Pusat?

2. Bagaimana pengaruh disiplin kerja terhadap kinerja karyawan pada PT. Ramayana Lestari SentosaTbk di Jakarta Pusat?

3. Bagaimana pengaruh komunikasi dan disiplin kerja terhadap kinerja karyawan pada
PT. Ramayana Lestari

SentosaTbk di Jakarta Pusat?

\section{Tujuan Dari Penelitian}

Adapun tujuan penelitian yang ingin dicapai dalam penelitian ini adalah:

1. Untuk mengetahui pengaruh komunikasi atas kinerja karyawan pada PT. Ramayana Lestari SentosaTbk di Jakarta Pusat.

2. Untuk mengetahui pengaruh disiplin kerja atas kinerja karyawan PT. Ramayana Lestari Sentosa Tbk di Jakarta Pusat.

3. Untuk mengetahui pengaruh komunikasi dan disiplin kerja atas kinerja karyawan pada PT. Ramayana Lestari Sentosa Tbk di Jakarta Pusat.

\section{TINJAUAN PUSTAKA}

A. Pengertian Manajemen Sumber Daya Manusia

Manajemen sumber daya manusia merupakan salah satu bidang dari manajemen umum yang meliputi segi-segi perencanaan, pengorganisasian, pelaksanaan dan pengendalian (Rivai, 2014:10). 
Manajemen sumber daya manusia sebagai kebijakan dan latihan untuk memenuhi kebutuhan karyawan atau aspek-aspek yang terdapat dalam sumber daya manusia seperti posisi manajemen, pengadaan karyawan atau rekrutmen, penyaringan, pelatihan, kompensasi, dan penilaian prestasi kerja karyawan (Dessler, 2015:4).

Berdasarkan pengertian tersebut dapat disimpulkan jika MSDM mengatur semua tenaga kerja secara efektif dan efisien dengan mengembangkan kemampuan yang mereka miliki dalam mewujudkan tujuan perusahaan, karyawan, dan masyarakat. Dengan memiliki tujuan tertentu maka tenaga kerja akan termotivasi untuk bekerja sebaik mungkin.

\section{B. Pengertian Komunikasi}

Komunikasi memungkinkan pertukaran tatap muka, memupuk semangat persahabatan dan mendorong pertanyaan dan jawaban.Rapat-rapat formal dalam sebuah organisasi sudah jadi biasa.Ini adalah sejalan dengan penilaian tinggi yang waktu diberikan ini kepada pembuatan keputusan berkelompok, yang mendorong partisipasi kelompok, dan tetap memberitahukan para pegawai mengenai sesuatunya(Rakhmat, 2018:1).

\section{Pengertian Disiplin Kerja}

Menurut Machmed (2014:143), berdasarkan definisi para ahli, "Disiplin kerja adalah suatu kondisi dimana karyawan bersedia menerima, dan melaksanakan berbagai peraturan yang ada, baik yang dinyatakan secara kingkrit maupun kebiasaan yang sudah menjadi budaya, dan berhubungan dengan pelaksanaan tugas, wewenang, tanggung jawab terhadap perusahaan".

Hal tersebut sependapat dengan Busro (2018:55), "Disiplin kerja adalah suatu sikap kejiwaan yang senantiasa berkehendak untuk mematuhi atau mengikuti segala peraturan yang telah ditentukan.

Berdasarkan pendapat para ahli, penulis dapat menyimpulkan bahwa disiplin kerja merupakan suatu sikap, tingkah laku, dan perbuatan yang sesuai dengan peraturan baik tertulis maupun tidak tertulis, dan bila melanggar akan ada sanksi atas perbuatannya.

\section{METODE PENELITIAN}

Penelitian karya ilmiah ini dibuat dengan memakai pendekatan metode survei. Jenis dari penelitian ini dibuat menggunakan jenis penelitian asosiatif. Semua karyawan di PT. Ramayana lestari sentosa Tbkyang beralamat di beralamat di Jl. K.H Wahid Hasyim No-220 A-B Rt.009 Rw.07 kel. Kampung Bali, kec. Tanah Abang kota Jakarta Pusat 10250dengan populasi yang total jumlahnya adalah50 orang dari Divisi Pajak serta dengan memakai metode samplingjenuh dengan jumlah total sampel sebanyak 50 responden.

Didalam penelitian ini metode pengumpulan data-datayang digunakan adalah sebagai berikut:

1. Observasi yaitu mengamati langsung PT. Ramayana lestari sentosa Tbk yang hanya terbatas pada inti permasalahan sehingga perhatian terfokus kepada data (riil) dan relevan.

2. Daftar kuesioner yang disampaikan kepada para karyawan Divisi Pajak PT. Ramayana lestari sentosa Tbkyang dijadikan sampel. 
3. Dokumentasisebagai penunjang untuk memperoleh data tentang sejarah perusahaan, jumlah karyawan, dan lain sebagainya.

4. Studi Kepustakaan, mencari landasan teoritis yang berhubungan dengan judul penelitian.

\section{HASIL PENELITIAN}

A. Uji Validitas dan Reliabilitas

1. Uji validitas Berdasarkan Variabel Komunikasi $\left(\mathrm{X}_{1}\right)$

Tabel 4.1Hasil Uji Validitas Berdasarkan Variabel Komunikasi (X1)

\begin{tabular}{|c|c|c|c|}
\hline Leten Kanisuer & 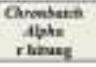 & 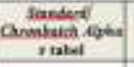 & Kngatuana \\
\hline 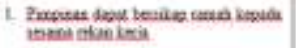 & 0.58 & 0.215 & vesu \\
\hline 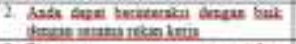 & 0.93 & 0.279 & veld \\
\hline 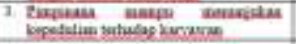 & a.t3t & 6.21s & Shath \\
\hline 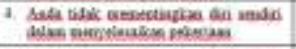 & a.tis & 0.278 & Veat \\
\hline 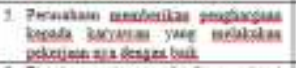 & 0.00 & 0.28 & vasu \\
\hline 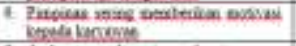 & Quas: & 0.238 & vals \\
\hline 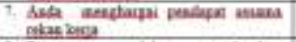 & ast & $0.2 \%$ & Vust \\
\hline 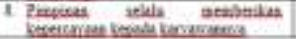 & $0 . \div 0$ & 0218 & vas \\
\hline
\end{tabular}

Sumber: Data Primer diolah, 2019.

Tabel 4.1 menunjukkanitem pada kuesioner layak digunakan sebaga alat penelitian.

2. Uji Validitas Berdasarkan Variabel Disiplin Kerja (X2)

Tabel 4.2

Hasil Uji Validitas Berdasarkan Variabel Disiplin Kerja (X2)

\begin{tabular}{|c|c|c|c|}
\hline liem Konsicant & $\begin{array}{l}\text { Chroethateh } \\
\text { Atpta } \\
\text { rinuas }\end{array}$ & $\begin{array}{l}\text { Sandar: } \\
\text { Chrovlasth } \\
\text { Alate } \\
\text { flatel }\end{array}$ & Kequitan \\
\hline 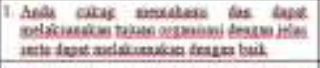 & $9 \sin 6$ & טגו & Yout \\
\hline 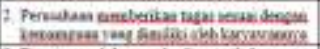 & 0.300 & asy & vata \\
\hline 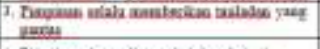 & 0.474 & axy & Vaid \\
\hline 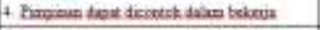 & as.56 & 0.20 & Valut \\
\hline 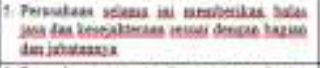 & a 404 & 620 & Yalad \\
\hline 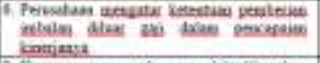 & assi & a2s & Valad \\
\hline 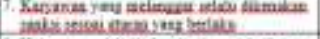 & 9000 & 0200 & vous \\
\hline 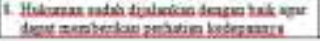 & $a=0$ & 120 & valu \\
\hline
\end{tabular}

Sumber: Data Primer diolah, 2019.
Dari tabel 4.2 menunjukkan data per item dari kuesioner layak digunakan sebagai alat penelitian.

3. Uji Validitas Berdasarkan Variabel Kinerja Karyawan (Y)

Tabel 4.3

Hasil Uji Validitas Berdasarkan Variabel Kinerja Karyawan (Y)

\begin{tabular}{|c|c|c|c|}
\hline Hem Kuniosur & $\begin{array}{l}\text { Caroshatch } \\
\text { Alpha } \\
\text { rhitaig }\end{array}$ & 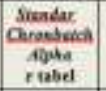 & Kequiman \\
\hline 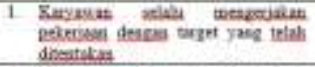 & 0.000 & 0259 & Vatid \\
\hline 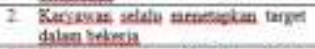 & 0,639 & 0.279 & Valid \\
\hline 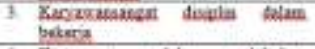 & 0.510 & 027 & Valis \\
\hline 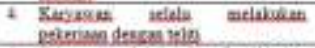 & 0.770 & 0.279 & Valide \\
\hline 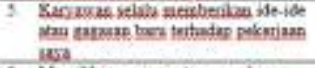 & 0.333 & 0.279 & Valia \\
\hline 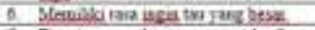 & 060 & 62.99 & Velie \\
\hline 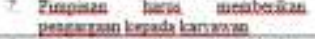 & 0.516 & 0.279 & Vatite \\
\hline 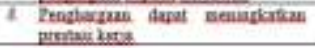 & 0 ast & 0.279 & Valia \\
\hline
\end{tabular}

Sumber: Data Primer diolah, 2019.

Tabel 4.3, menunjukkan nilai data kuesioner layak digunakan sebagai alat penelitian.

4. Uji Reliabilitas Instrumen Tabel 4.4

Hasil $\mathrm{cju}$ Retiasaitas Variabel Iadependen das Dependen

\begin{tabular}{|c|c|c|c|c|}
\hline $\mathrm{Na}$ & Variabel & $\begin{array}{c}\text { Coefirient } \\
\text { Alpha } \\
\text { r hituag }\end{array}$ & $\begin{array}{l}\text { Standat } \\
\text { Chroubuch } \\
\text { Apha } \\
\text { riabel }\end{array}$ & Kepputasses \\
\hline 1 & Komunikasi (X1) & 0.615 & 0.279 & Relisbel \\
\hline 2 & Deaplat Kerja $(X 2)$ & 0,582 & 0.279 & \begin{tabular}{|l|} 
Reliabel \\
\end{tabular} \\
\hline 3 & Kineja Karyawan (Y) & 0.700 & 0.279 & Reliabel \\
\hline
\end{tabular}

Tabel 4.4 menunjukkan bahwa nilai $\mathrm{r}$ hitung $>\mathrm{r}$ tabel $(0,279)$, sehingga kuesioner layak digunakan sebagai alat penelitian.

\section{B. Uji Prasyarat Data}

1. Uji Normalitas 
Jurnal Semarak,Vol. 3,No.1, Februari 2020, Hal (75- 81)

@Prodi Manajemen Fakultas Ekonomi Universitas Pamulang

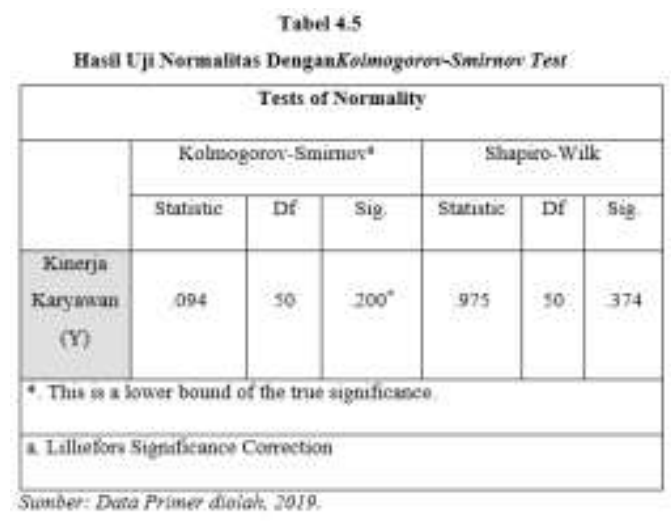

Tabel 4.5, menunjukkan data terdistribusi normal.

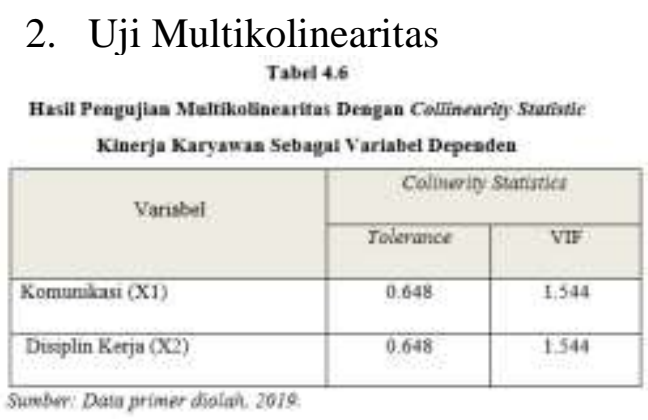

Tabel 4.6, disimpulkan jika dari hasil model regresi ini tidak ada multikolinearitas.

\section{Uji Autokorelasi}

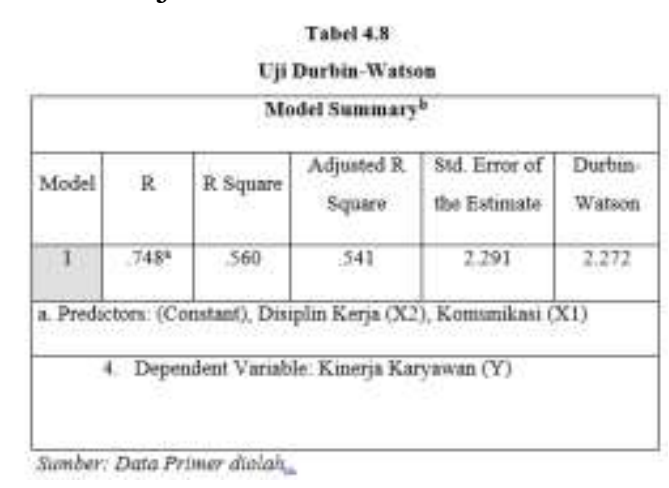

Tabel 4.8, menunjukkantidak ada autokorelasi.

4. Uji Heteroskedastisitas

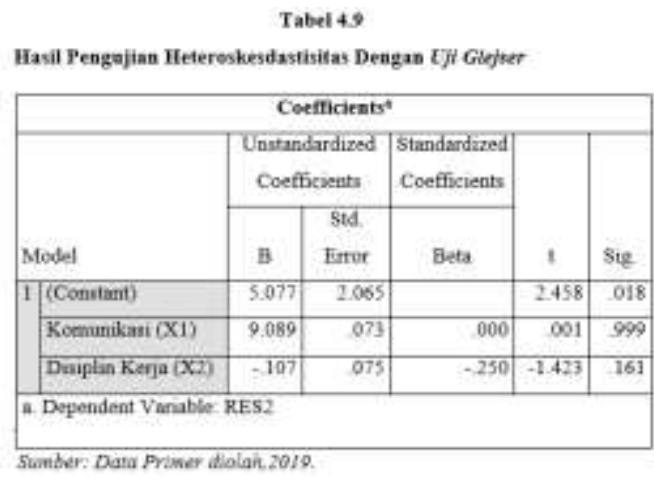

Dari tabel 4.9, dengan glejsertestmodel diperoleh nilai probabilitysignifikansi (Sig.) sebesar 0,999 pada variabel komunikasi (X1) dan disiplin kerja (X2) diperoleh nilai probability signifikansi (Sig.) sebesar 0,161 dimana keduanya nilai signifikansi (Sig.) > 0,05. Data tersebut membuktikan jika tidak ada gangguan heterokedastisitas, sehingga model regresi ini layak digunakan sebagai alat penelitian.

\section{Pengujian Hipotesis}

1. Pengaruh Komunikasi (X1) Terhadap Kinerja Karyawan (Y)

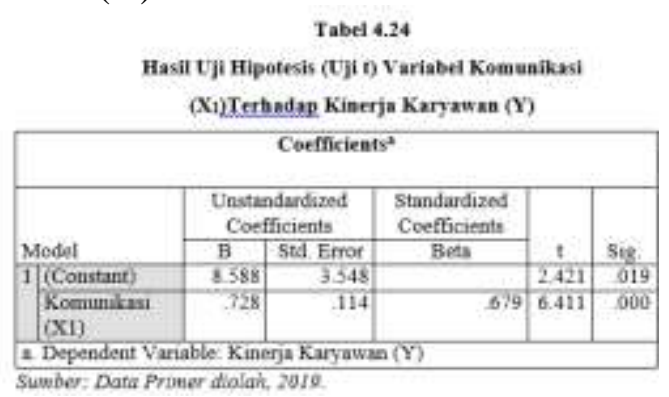

Dari Tabel 4.24, diambil kesimpulan, $\mathrm{H}_{0}$ ditolak dan $\mathrm{H} 1$ diterima. Tabel menunjukkan diperoleh nilai $t_{\text {hitung }}>t_{\text {tabel. }}$ Hal tersebut juga diperkuat dengan nilai $\rho_{\text {value }}<$ Sig. 0,05 atau $(0,000<$ $0,05)$.Artinya adapengaruh positif dan signifikan secara parsial antara 
Jurnal Semarak,Vol. 3,No.1, Februari 2020, Hal (75- 81)

@Prodi Manajemen Fakultas Ekonomi Universitas Pamulang

variabel X1 (komunikasi) terhadap variabel Y (kinerja karyawan) pada PT. Ramayana lestari sentosa Tbk.

2. Pengaruh Dsiplin Kerja (X2) Terhadap Kinerja Karyawan (Y)

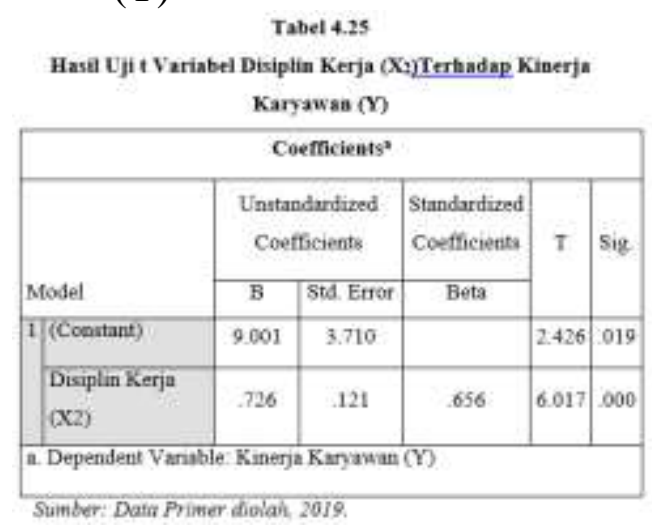

Pada table 4.25, diperoleh nilai $t_{\text {hitung }}>t_{\text {tabel }}$ atau $(6,017>$ 2,011).Dengan demikian, $\mathrm{H}_{0}$ ditolak dan $\mathrm{H}_{2}$ diterima. Kesimpulannya, ada pengaruh yang positif dan signifikan secara parsial.

\section{Pengujian Hipotesis Secara Simultan}

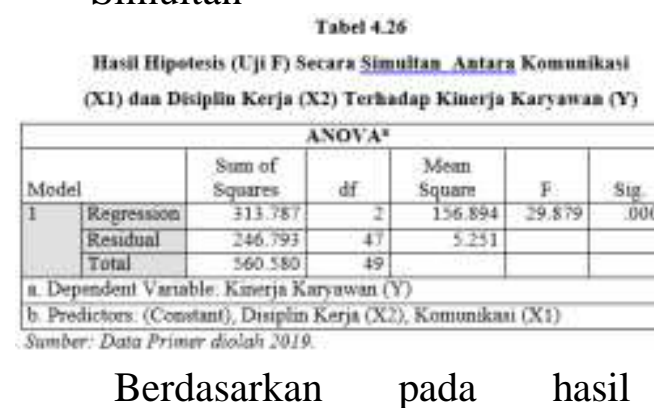
pengujian pada tabel di atas diperoleh nilai $F_{\text {hitung }}>F_{\text {tabel }}$ atau $(29.879>2,800)$, hal ini juga diperkuat dengan $\rho$ value $<$ Sig. 0,05 atau $(0,000<0,05)$. Dengan demikian maka $\mathrm{H}_{0}$ ditolak dan $\mathrm{H}_{3}$ diterima, hal ini menunjukkan bahwa terdapat pengaruh positif dan signifikan.

\section{KESIMPULAN DAN SARAN}

A. Kesimpulan

1. Komunikasi (X1) berpengaruh positif dan signifikan terhadap kinerja kerja karyawan (Y) dengan nilai korelasi sebesar 0,679 artinya memiliki pengaruh yang kuat dengan koefisien determinasi sebesar 46,1\%. Dengan demikian $\mathrm{H}_{0}$ ditolak dan $\mathrm{H} 1$ diterima artinya terdapat pengaruh positif dan signifikan antara komunikasi terhadap kinerja karyawan pada PT. Ramayana Lestari SentosaTbk di Jakarta Pusat.

2. Uji hipotesis di peroleh $t$ hitung $>\mathrm{t}$ tabel atau $(6,017>2,011)$, hal ini di perkuat dengan probabilitysignifikansi $0,000<0,05$.

3. Ada pengaruh positif dan signifikan terhadap kinerja karyawan(Y)dengan persamaan regresi $\mathrm{Y}=3,090+0,480 \mathrm{X} 1+$ 0,432 X2. Nilai korelasi diperoleh sebesar 0,748 artinya variabel bebas dengan variabel terikat memiliki pengaruh yang kuat atau pengaruh secara simultan sebesar $56 \%$ sedangkan sisanya sebesar $44 \%$ di pengaruhi faktor lain. Artinya terdapat pengaruh positif dan signifikan secara simultan antara komunikasi dan disiplin kerja terhadap kinerja karyawan pada PT.Ramayana Lestari SentosaTbk di Jakarta Pusat.

\section{B. Saran}

Dalam usaha meningkatkan produktiviitas kerja karyawan Divisi Pajak PT. Ramayana Lestari Sentosa Tbk maka perusahaan hendaknya :

1. Pada kuesioner nomor 3 yaitu Pimpinan tidak mampu menunjukan kepedulian terhadap karyawannya di mana hanya mencapai rating scoreterendah 
yaitu 3,80. Sebaiknya diganti dengan pertanyaan lain yang relevan dengan kisi-kisi kuesioner.

2. Pada item no. 2 yaitu Perusahaan tidak memberikan tugas sesuai dengan kemampuan yang dimiliki oleh karyawannyahanya mencapai scoreterendah 3,72. Sebaiknya diganti dengan pertanyaan lain yang relevan dengan kisi-kisi kuesioner.

3. Pada kuesioner nomor 5 yaitu Karyawan selalu memberikan ideide atau gagasan baru terhadap pekerjaan hanya memperolehscoreterendah 3,80.Sebaiknya diganti dengan pertanyaan lain yang relevan dengan kisi-kisi kuesioner.

4. Nilai ini masih bisa di tingkatkan dengan cara pimpinan mampu memberikan kepedulian terhadap karyawannya, pemberian tugas sesuai dengan potensi yang di miliki oleh karyawannya, dan karyawan juga harus berani menyampaikan gagasan yang dapat membantu perusahan mencapai tujuan yang ingin di capai.

\section{DAFTAR PUSTAKA}

Arikunto, S., "Prosedur Penelitian Suatu Pendekatan Praktek”, PT. Rineka Cipta, Jakarta, 2015.

Dessler, G., "Human Resources Management", Prenticehall, International Inc, London, 2014.

Ghozali, I., "Aplikasi Analisis Multivariate dengan Program SPSS", Edisi Kelima, Badan Penerbit Undip, Semarang, 2014. Hasibuan, "Sumber Daya Manusia", Haji Masagung, Jakarta, 2016. Machmed,"Manajemen Sumber Daya
Manusia (Konsep dan Realita)",Penerbit In Media, Jakarta, 2014.

Mathis, R. L \& Jackson, J.H, "Manajemen Sumber Daya Manusia" Jilid 1, Salemba Empat, Jakarta, 2014.

Rivai, V., "Manajemen Sumber Daya Manusia Untuk Perusahaan", Raja Grafindo Persada, Jakarta, 2013.

Simamora, B., "Panduan Riset Dan Perilaku Konsumen”, PT. Gramedia Pustaka Utama, Jakarta, 2014.

Santoso, S., "SPSS Statistik Parametik" Cetakan Kedua, PT. Elek Media, Jakarta, 2013.

Sugiyono, "Metode Penelitian Kuantitatif Kualitatif dan $R$ \& D", Penerbit CV. Alfabeta, Bandung, 2016.

Supangat, A., "Statistika dalam Kajian Deskriftif, Inferensi dan Non Parametric", Edisi Pertama, Kencana Prenada Media Group, Jakarta, 2014

\section{Jurnal}

Friska, Jurnal Sultanist, 2016, ISSN: 2338-4328 Vol.5 No.2, Pengaruh Komunikasi dan Disiplin Kerja Terhadap Kinerja Karyawan Pada Café Kopi Massa Koktong Lim Ming Pematang siantar.

I Ketut Sirna, Jurnal MAnajemen dan Bisnis, ISSN:1978-6069, Vol.12, No.2. Agustus 2017, Pengaruh disiplin kerja dan motivasi terhadap produktivitas kerja karyawan di hotel Patra Jasa Bali resort \& Villas.

Ismail Usman, Jurnal Ilmu Administrasi Bisnis, ISSN:23555408. Vol. 4, No.3, 2016: 911922. Pengaruh Disiplin Kerja Terhadap Produktivitas Kerja 
Karyawan Pada PT Allo Jaya di Bontang.

Lu Mang, Jurnal Manajemen unud, ISSN:2302-8912. Vol. 6, No.7, 2017: 3540-3569. Pengaruh Motivasi, Komunikasi dan Disiplin Kerja Terhadap Kinerja Karyawan Warung Mina Penguyungan Denpasar.

Nurmaidah, Jurnal AJIE, ISSN:24770574. Vol. 3, No. 2, 2018: 24773824. Pengaruh Disiplin Kerja dan Komunikasi Terhadap Kinerja Karyawan PT. Sekar Mulia Abadi Medan.

Pasaribu, V. L. D., \& Krisnaldy, K. (2018). ANALISIS KEPUASAN JAMA'AH PADA KINERJA DEWAN KEMAKMURAN MASJID AL-HIDAYAH PERIODE TAHUN 2017. KREATIF: Jurnal Ilmiah Prodi Manajemen Universitas Pamulang, 6(4), 41-51.

Pasaribu, V. L. D., Krisnaldy, K., \& Warasto, H. N. (2020). Pengaruh Gaya Kepemimpinan, Disiplin Kerja Dan Kompensasi Terhadap Kinerja Pegawai (Studi kasus kelurahan Pisangan Ciputat). Disrupsi Bisnis, 3(1). 